\section{Meconium Plug}

\section{Kshirsagar VY', Ahmed $\mathbf{M}^{2}$, Colaco $\mathrm{SM}^{3}$, Patil $\mathrm{S}^{4}$}

${ }^{1}$ Dr. Vinayak Y Kshirsagar, MBBS, MD, Professor and Head of Department, ${ }^{2} \mathrm{Dr}$. Minhajuddin Ahmed, MBBS, MD, ${ }^{3}$ Dr. Sylvia. M. Colaco, MBBS, MD, ${ }^{4}$ Dr. Shriganesh Patil, MBBS, MD Resident. All from the Department of Paediatrics, Krishna Institute of Medical Sciences University, Krishna Hospital, Karad, Maharashtra-415110. India.

$\mathrm{M}$ econium plug (MP) is a transient form of distal colonic or rectal obstruction caused by a tenacious mass of mucus in the distal colon or rectum preventing the passage meconium from the proximal part of the colon. Features of MP are similar to features of intestinal obstruction. A $3.980 \mathrm{~kg}$ male neonate born to a primigravida non-diabetic mother was admitted for asymptomatic hypoglycemia. On day 2 child was noticed not to be tolerating feeds, with bilious vomiting, abdominal distension and yet to pass meconium. Plain abdominal X-ray erect and supine shows gaseous distension of the bowel loops and absence of gas beyond descending colon. (Figure 1)

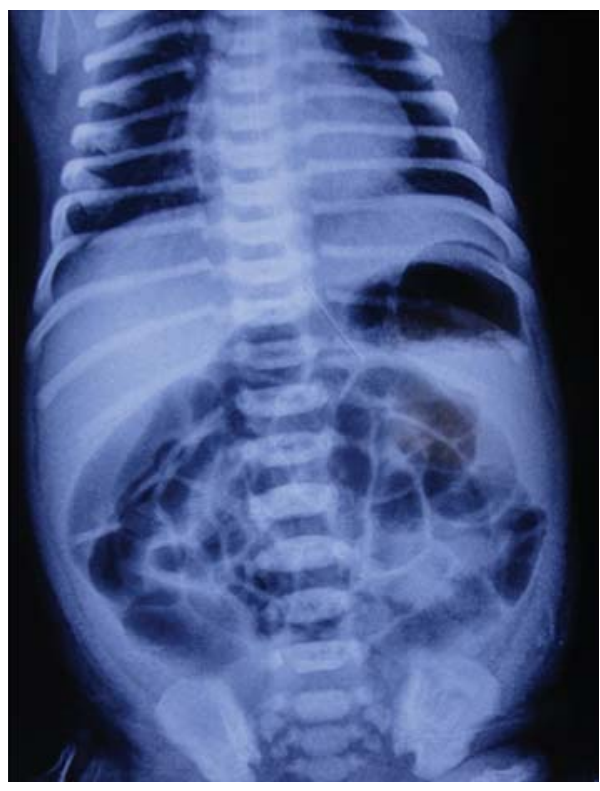

Fig 1: X-ray erect abdomen

\section{Address for correspondence}

Dr. VY Kshirsagar

E-mail:drkshirsagarvy@yahoo.com

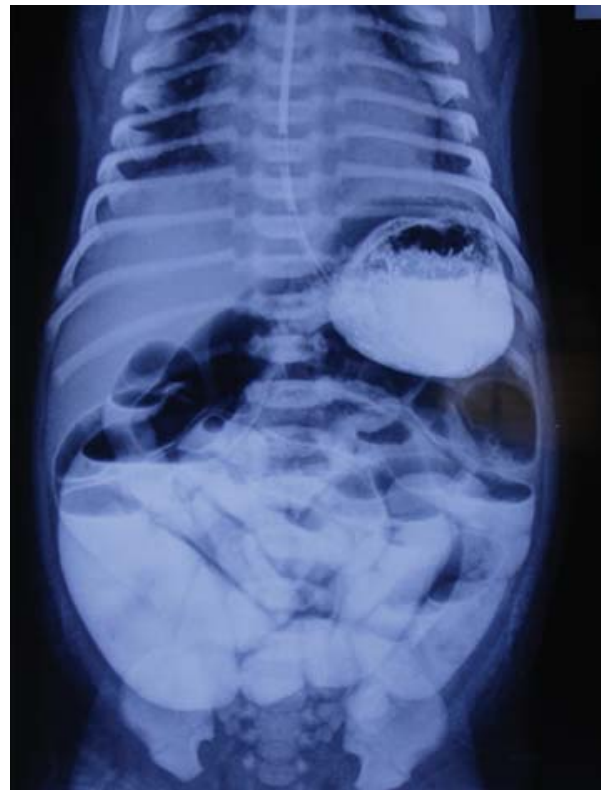

Fig 2: X-ray after gastrograffin ingestion

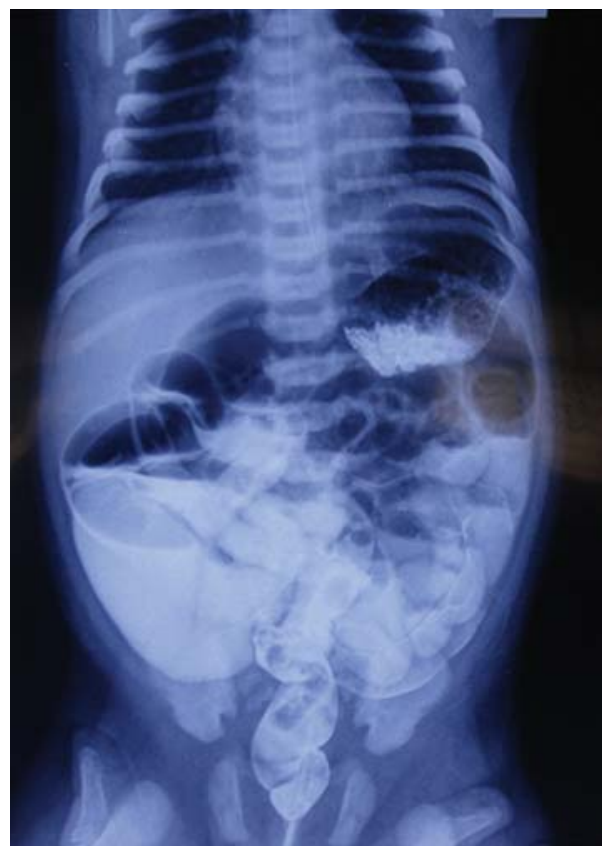

Fig 3: X-ray after gastrograffin enema 
Gastrograffin dye was inserted through the Ryle`s tube under adequate hydration and X-ray showed no dye beyond sigmoid colon. (Figure 2) So a Gastrograffin enema was given and dye was visualized in the rectum and sigmoid colon. (Figure 3)

In the mean time baby passed thick gelatinous meconium plug measuring $22 \mathrm{cms}$ (Figure 4) followed by large amount of meconium. The activity of the baby improved thereafter with reduction of abdominal girth from 35.4 to $32.6 \mathrm{cms}$. The baby was put to breast and accepted feeds well and was discharged on day 9 of life. The differential diagnosis of failure or delayed passage of meconium like Hirschsprung's disease, meconium plug syndrome, meconium ileus, anorectal malformation, small left colon syndrome, hypoganglionosis, neuronal intestinal dysplasia, and megacystis- microcolon- intestinal hypoperistalsis syndrome should be considered in such conditions. But a diagnosis of MP should be considered before taking up a patient of suspected intestinal obstruction for surgery.

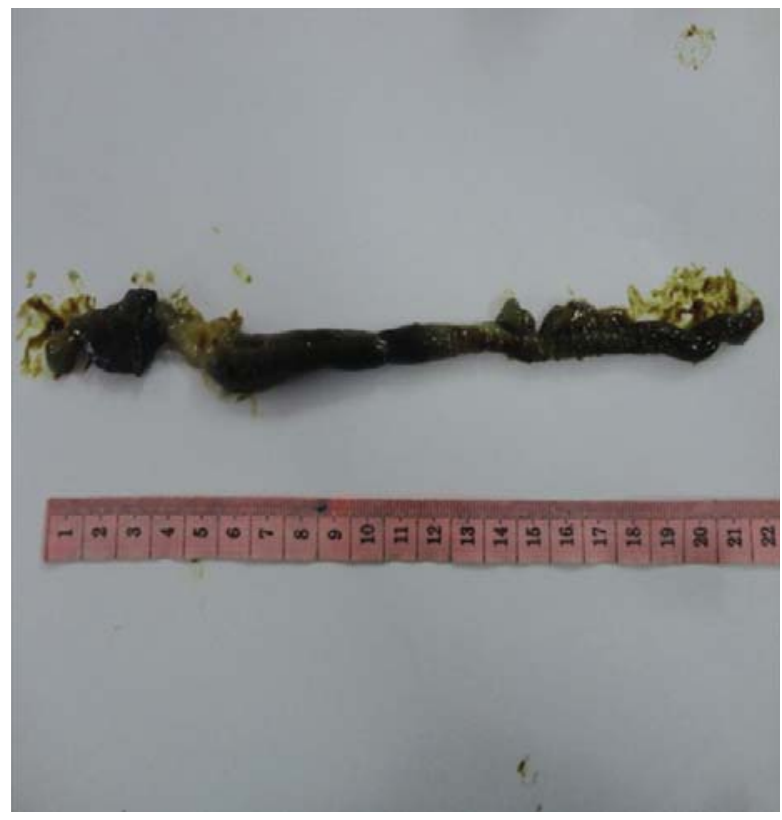

Fig 4: $22 \mathrm{cms}$ Meconium plug 